\title{
Visualisation of the distribution of minerals in red non-tannin finger millet using PIXE microanalysis
}

\author{
Johanita Kruger $^{\mathrm{a}}$, Carlos Pineda-Vargas ${ }^{\mathrm{b}}$, Roya Minnis-Ndimba ${ }^{\mathrm{b}}$ and John RN Taylor ${ }^{\mathrm{a}}$ \\ ${ }^{a}$ Department of Food Science and Institute for Food, Nutrition and Well-being, University of Pretoria, \\ Private Bag X20, Hatfield 0028, South Africa \\ ${ }^{\mathrm{b}}$ Materials Research Department, iThemba LABS, NRF, Somerset West 7129, South Africa. \\ *Corresponding author: johanita.kruger@up.ac.za, Tel: + 2712 420-5402, Fax: +27 124202839
}

Key words: Finger millet, Mineral distribution, PIXE

Finger millet (Eleusine coracana), a small grained tropical cereal widely cultivated in Africa and India, has recently received considerable interest on account of its nutritional value, potential health benefits and role in food security (Chandrashekar, 2010; Shobana et al., 2012). It has been reported to have an unusual and nutritionally beneficial mineral composition, with higher levels of $\mathrm{Ca}$ and $\mathrm{K}$ than any other cereal (Shobana et al., 2012). Calcium is thought to play a vital role in reducing the prevalence of rickets, which is still high in developing countries, despite sufficient UV light for vitamin D production (Pettifor, 2004). Positive $\mathrm{K}$ status has been found to reduce the risk of diabetes, cardiovascular and renal disease (He \& McGregor, 2008), which is particularly important in developing countries increasingly suffering under the double burden of under- and over-nutrition (Shrimpton \& Rokx, 2013). Another millet, pearl millet has been successfully biofortified with increased Fe and $\mathrm{Zn}$ contents (Rai et al., 2011). Biofortified pearl millet has been found to have improved Fe and Zn bioavailability (Cercamondi, 2013) and increased absorption (Kodkany, 2013). 
In general, knowledge of the distribution of essential minerals in grains is limited (Cvitanich et al., 2011). Such information, however, is crucial for understanding the molecular mechanisms responsible for the micronutrient accumulation. Proton induced $\mathrm{x}$-ray emission spectrometry (PIXE) is a non-destructive technique, which not only provides a visual map of the mineral distribution, but also provides quantitative data of the mineral concentrations (Ryan, 2011). The small size of finger millet makes it possible to map the entire kernel. To our knowledge there are no publications where the mineral distribution of an entire cereal kernel has been visualised and quantified using PIXE. Thus, the primary aim of this study was to determine if the mineral distribution of the entire finger millet kernel could be mapped using PIXE. Mapping an entire kernel would also provide unique insight on mineral distribution in this important cereal.

Whole kernels of two non-tannin red finger millet varieties, Tadesse-KNE\#1098 and PadetKNE\#409, from the Ethiopian Agricultural Research Institute were obtained free from the pericarp. Tannin (Price et al., 1978), total phenolic (Kaluza et al., 1980) and phytate (Frubeck et al., 1995) contents were determined. Mineral contents were analysed by ion coupled plasma-optical emission spectrometry (ICP-OES, SPECTRO Analytical Instruments, Kleve, Germany). The mineral distribution in the grains were mapped by PIXE (Materials Research Department, iThemba LABS, South Africa). The grains were embedded with a commercial resin (Epofix ${ }^{\mathrm{TM}}$ Struers), cut longitudinally and coated with a thin layer of carbon. The whole kernel's cut surface (approx. $2 \mathrm{~mm}^{2}$ ) was raster scanned using a proton microbeam, with an energy of $3.0 \mathrm{MeV}$ whilst a smaller area $\left(0.8 \mathrm{~mm}^{2}\right)$ was scanned using an energy of $1.5 \mathrm{MeV}$. The beam was focused to a minimum spot size of $3 \mu \mathrm{m}^{2}$ with an approximative current of $100 \mathrm{pA}$. Scanned areas were typically analysed in a square pattern, of up to $128 \times 128$ pixels, with a dwell time of $10 \mathrm{~ms} /$ pixel. For elemental mapping, PIXE and proton backscattering spectra were acquired simultaneously in event-by-event mode, using a Si (Li) X-ray detector shielded with either a $25 \mu \mathrm{m}$ Be filter (irradiations with $1.5 \mathrm{MeV}$ protons) or a 125 um Be filter (irradiations with $3.0 \mathrm{MeV}$ protons). The PIXE count rate was 
kept below 1000 counts/second to circumvent pulse pile-up and to achieve satisfactory counting statistics. Samples were irradiated with a total charge between 0.5 and $4 \mu \mathrm{C}$. The accumulated PIXE spectra were analysed using GeoPIXE II software (Ryan, 2001). The setup used a thick sample description and the sample matrix was assumed to be comparable to cellulose.

While significantly different, the phytate, phenolic, tannin and mineral contents (Table 1) of the two finger millet varieties were similar. The phytate contents also fell within previously reported ranges for finger millet $(242-1310 \mathrm{mg} / 100 \mathrm{~g})$ (Mamiro et al., 2001; Shashi et al., 2007). The mineral contents fell within the previously reported ranges: Ca (240-532 mg/100 g), Zn (0.9-2.9 mg/100 g), Fe (3.3-20 mg/100 g), P (130-325 mg/100 g) and Mg (66-183 mg/100 g) (Ravindran, 1991; Mamiro et al., 2001; Shashi et al., 2007; Glew et al., 2008; Shobana et al., 2012).

Table 1: Mineral, total phenolic, phytate and condensed tannin contents (dry basis) of finger millet

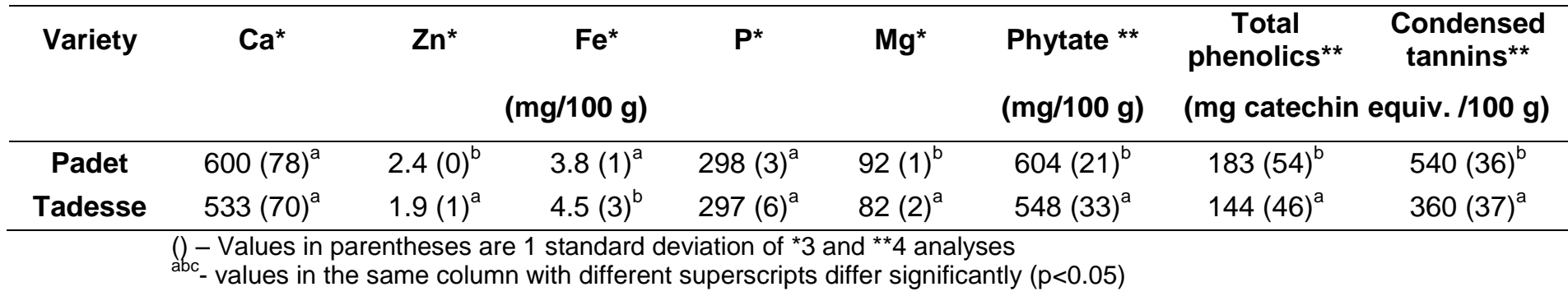

PIXE analysis did not reveal any significant aluminium contents or patterns (results not shown). This indicated the mineral contents were not altered due to soil or dust contamination or inclusions (Cary et al., 1994). Thus, the mineral distributions were a true representation of what is actually present in the kernel.

The elemental maps of both the finger millet varieties were very similar, as is clear in the comparison of the $\mathrm{K}$ maps (Figure 1). PIXE analysis, however, did reveal that the high levels of Ca (Table 1$)$ were located mainly in the seed coat $(\approx 750-3750 \mathrm{mg} / 100 \mathrm{~g})$ and to a lesser extent in the endosperm ( $\approx 250-750 \mathrm{mg} / 100 \mathrm{~g})$, with no Ca in the germ (Figure 1). 

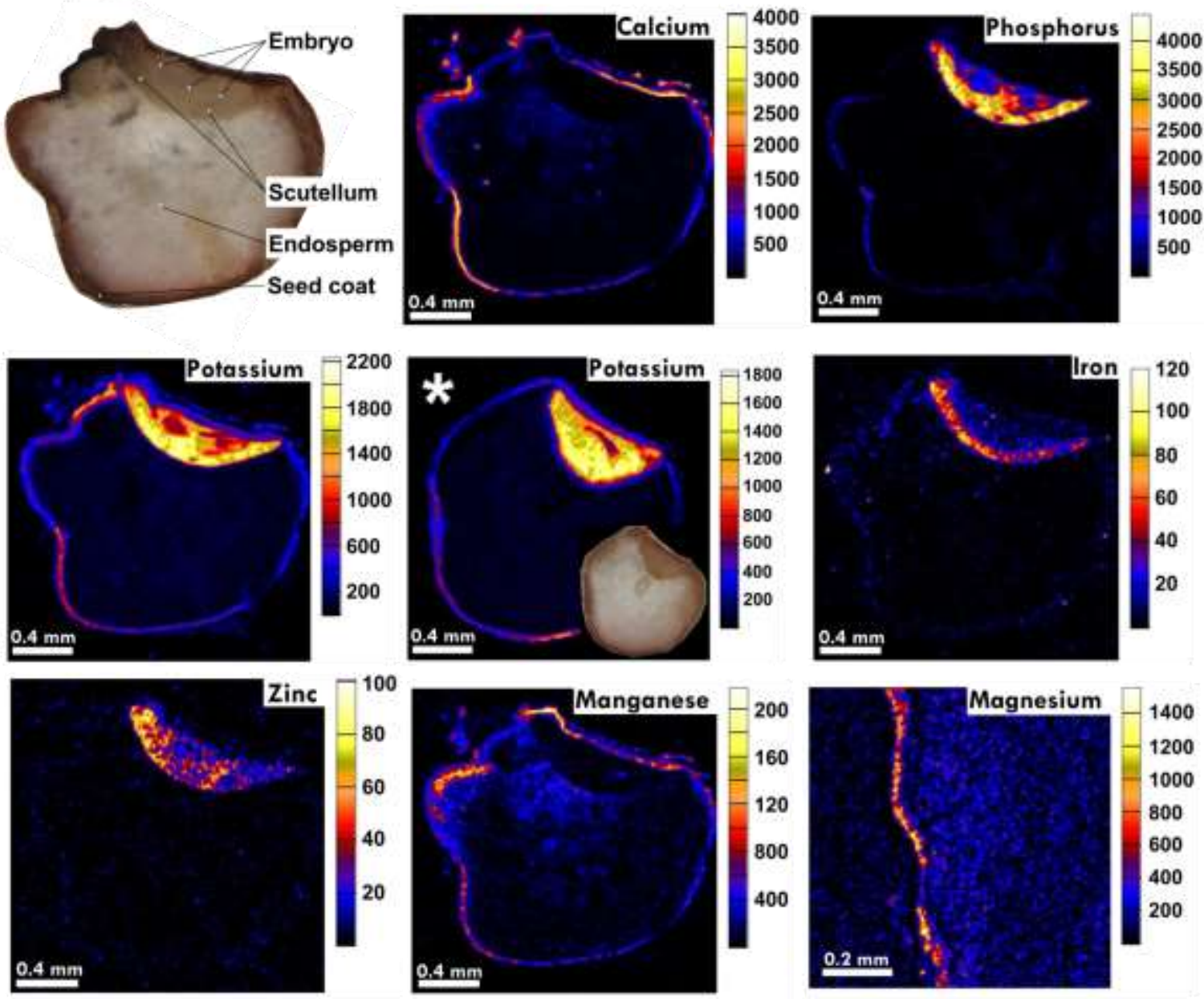

Figure 1: Quantitative visualisation, with concentration scales units $\mathrm{mg} / 100 \mathrm{~g}$, of the mineral distribution in a representative grain of red non-tannin Tadesse finger millet cut longitudinally. *Elemental map of $\mathrm{K}$ for Padet finger millet.

Phosphorus was located mainly in the scutellum $(\approx 1500-4400 \mathrm{mg} / 100 \mathrm{~g})$ with very low concentrations sparsely scattered through the endosperm. Phytate is the main storage form of $\mathrm{P}$ (Oatway, 2001) and importantly, the $\mathrm{Ca}$ in the endosperm of the finger millet would be less likely to be bound by phytate (O'Dell et al., 1972) and probably be more bioavailable. The high concentrations of $\mathrm{K}$ in the scutellum $(\approx 1300-2200 \mathrm{mg} / 100 \mathrm{~g})$, embryo $(\approx 600-1600$ $\mathrm{mg} / 100 \mathrm{~g})$, and seed coat $(\approx 500-1600 \mathrm{mg} / 100 \mathrm{~g})$, together with the even distribution at 
relatively high concentrations $(\approx 300 \mathrm{mg} / 100 \mathrm{~g})$ in the endosperm, agreed with the reported high $\mathrm{K}$ concentrations in finger millet (Shobana et al., 2012).

Iron was located mainly in the scutellum $(\approx 30-110 \mathrm{mg} / 100 \mathrm{~g})$, but also scattered unevenly through the rest of the grain $(\approx 0-30 \mathrm{mg} / 100 \mathrm{~g})$. Zinc was located throughout the germ (scutellum and embryo) ( $\approx 20-100 \mathrm{mg} / 100 \mathrm{~g})$ and like Fe, scattered through the rest of the grain, but more evenly $(\approx 0-20 \mathrm{mg} / 100 \mathrm{~g})$. The $\mathrm{Mn}$ was mostly located in the seed coat $(\approx 40-$ $200 \mathrm{mg} / 100 \mathrm{~g}$ ) and similar to $\mathrm{Ca}$, almost no Mn was located in the germ. Lastly, higher concentrations of $\mathrm{Mg}$ were observed in the seed coat $(\approx 40-1500 \mathrm{mg} / 100 \mathrm{~g})$ compared to the endosperm $(\approx 10-70 \mathrm{mg} / 100 \mathrm{~g})$. Due to the fact that the analysis of the Mg content was performed with a $1.5 \mathrm{MeV}$ proton beam, which maximises the detection limit for light elements, the scanned area for the case of $\mathrm{Mg}$ was smaller than for all other maps. Consequently no information was obtained on the Mg distribution in the whole kernel.

PIXE analysis can successfully visualise and quantify the elemental distribution in an entire finger millet kernel. To our knowledge, this quantitative elemental map of finger millet by PIXE is the first of an entire cereal kernel. While there are PIXE elemental maps of parts of some cereal species, these maps are not quantitative (Singh et al., 2013). Apparently, the only PIXE quantitative elemental map, of a whole edible grain, is that of the pseudocereal buckwheat (Pongrac et al., 2012). The elemental mapping of finger millet has provided novel information, in particular that its content of $\mathrm{Ca}$ is in fact high and is distributed throughout the endosperm where phytate levels are low. This has important nutritional implications as $\mathrm{Ca}$ is deficient in the diet of many people, especially of those dependent on plant foods (Pettifor, 2004). Further, these findings demonstrate that mineral distribution mapping obtained by PIXE with a focused beam could be of value in research aimed at biofortifying staple cereal grains with essential minerals. 


\section{Acknowledgements}

The authors would like to thank the technical staff at the Materials Research Department, in particular Dr Chris Mtshali for his assistance during the PIXE measurements and the evaluation of data.

\section{References}

Cary, E.E., Grunes, D.L., Dallyn, S.L., Pearson, A., Peck, N.H., Hulm, R.S., 1994. Plant Fe, Al and Cr concentrations in vegetables as influenced by soil inclusion. Journal of Food Quality 17, 467-476.

Cercamondi, C.I., Egli, I.M., Mitchikpe, E., Tossou, F., Zeder, C., Hounhouigan, J.D., Hurrell, R.F., 2013. Total iron absorption by young women from iron-biofortified pearl millet composite meals is double that from regular millet meals but less than that from post-harvest iron-fortified millet meals. The Journal of nutrition $143,1376-1382$.

Chandrashekar, A., 2010. Finger millet: Eleusine coracana. Advances in Food and Nutrition Research $59,215-262$.

Cvitanich, C., Przybyłowicz, W.J., Mesjasz-Przybyłowicz, J., Blair, M.W., Astudillo, C., Orłowska, E., Stougaard, J., 2011. Micro-PIXE investigation of bean seeds to assist micronutrient biofortification. Nuclear Instruments and Methods in Physics Research Section B: Beam Interactions with Materials and Atoms 269, 2297-2302.

Frubeck, G., Alonso, R., Marzo, F., Santidrian, S., 1995. A modified method for the indirect quantitative analysis of phytate in foodstuffs. Analytical Biochemistry 225, 206-212.

Glew, R.S., Chuang, L.T., Roberts, J.L., Glew, R.H., 2008. Amino acid, fatty acid and mineral content of black finger millet (Eleusine coracana) cultivated on the Jos plateau of Nigeria. Global Science Books Food 2, 115-118.

He, F.J., MacGregor, G.A., 2008. Beneficial effects of potassium on human health. Physiologia Plantarum 133, 725-735.

Kaluza, W.Z., McGrath, R.M., Robberts, C., Schroeder, H.H., 1980. Separation of phenolics of sorghum bicolor (L.) Moench grain. Journal of Agricultural and Food Chemistry 28, 1191-1196. 
Kodkany, B.S., Bellad, R.M., Mahantshetti, N.S., Westcott, J.E., Krebs, N.F., Kemp, J.F., Hambidge, K.M., 2013. Biofortification of pearl millet with iron and $\mathrm{Zn}$ in a randomized controlled trial increases absorption of these minerals above physiologic requirements in young children. The Journal of Nutrition 143, 1489-1493.

Mamiro, P.R.S., Van, J., Mwikya, S.M., Huyghebaert, A., 2001. In vitro extractability of Ca, iron, and $\mathrm{Zn}$ in finger millet and kidney beans during processing. Journal of Food Science 66, 1271-1275.

Oatway, L., Vasanthan, T., Helm, J.H., 2001. Phytic acid. Food Reviews International 17, 419-431.

O'Dell, B.L., de Bowland, A.R., Koirtyohann, S.R., 1972. Distribution of phytate and nutritionally important elements among the morphological components of cereal grains. Journal of Agricultural and Food Chemistry 20, 718-721.

Pettifor, J.M., 2004. Nutritional rickets: deficiency of vitamin D, Ca, or both? The American Journal of Clinical Nutrition 80, 1725S-1729S.

Pongrac, P., Vogel-Mikuš, K., Jeromel, L., Vavpetič, P., Pelicon, P., Kaulich, B., Gianoncelli, A., Eichert, D., Regvar, M., Kreft, I., 2013. Spatially resolved distributions of the mineral elements in the grain of tartary buckwheat (Fagopyrum tataricum). Food Research International 54, 125-131.

Price, M.L., Van Scoyoc, S., Butler, L.G., 1978. A critical evaluation of the vanillin reaction as an assay for tannin in sorghum grain. Journal of Agricultural and Food Chemistry 26, 1214-1218.

Rai, K.N., Govindaraj, M., Rao, A.S. 2012. Genetic enhancement of grain iron and zinc content in pearl millet. Quality Assurance and Safety of Crops \& Foods 4, 119-125.

Ravindran, G., 1991. Studies on millets: Proximate composition, mineral composition, and phytate and oxalate contents. Food Chemistry 39, 99-107.

Ryan, C.G., 2001. Developments in dynamic analysis for quantitative PIXE true elemental imaging. Nuclear Instruments and Methods in Physics Research Section B: Beam Interactions with Materials and Atoms 181, 170-179. 
Ryan, C.G., 2011. PIXE and the nuclear microprobe: Tools for quantitative imaging of complex natural materials. Nuclear Instruments and Methods in Physics Research Section B: Beam Interactions with Materials and Atoms 269, 2151-2162.

Shashi, B.K., Sharan, S., Hittalamani, S., Shankar, A.G., Nagarathna, T.K., 2007. Micronutrient composition, antinutritional factors and bioaccessibility of iron in different finger millet (Eleusine coracana) genotypes. Karnataka Journal of Agricultural Sciences 20, 583.

Shobana, S., Krishnaswamy, K., Sudha, V., Malleshi, N.G., Anjana, R.M., Palaniappan, L., Mohan, V., 2012. Finger Millet (Ragi, Eleusine coracana L.): a review of its nutritional properties, processing, and plausible health benefits. Advances in Food and Nutrition Research 69, 1-39.

Singh, S.P., Vogel-Mikuš, K., Arčon, I., Vavpetič, P., Jeromel, L., Pelicon, P., Kumar, J., Tuli, R., 2013. Pattern of iron distribution in maternal and filial tissues in wheat grains with contrasting levels of iron. Journal of experimental botany $64,3249-3260$.

Shrimpton, R., Rokx, C., 2013. Double burden of malnutrition - A review of global evidence. HNP Discussion paper, World Bank, http:/tulane.edu/publichealth/internut/upload/08-04.pdf. (Feb, 2014)

Suma, P.F., Urooj, A., 2011. Nutrients, antinutrients \& bioaccessible mineral content (in vitro) of pearl millet as influenced by milling. Journal of Food Science and Technology, 1-6. 